\title{
Uma análise Crítica do Arcabouço Teórico do SFAS 133: Accounting for Derivative and Hedging Activities
}

\author{
Alexsandro Broedel Lopes \\ Doutorando em Controladoria e Contabilidade - FEA/USP USP \\ Pesquisador do Centro co Estudos e pesquisas \\ do Mercado Financeiro - FIPECAFI
}

Introducão

O objetivo deste trabalho e realizar um estudo do arcabouço

conceitual emanado do SFAS 133: Accounting for Derivatives Instruments and Hedging Activities. Procurou-se analisar o corpo teórico interior ao respectivo pronunciamento para em segui-la. após uma analise cuidadosa, realizar comparação entre ambos. Esta comparação não visa somente elencar os principais pontos contrastantes, mas, principalmente, critica-los e contextualizá-los na estrutura 'ia moderna Contabilidade.

No entanto, para o sucesso de qualquer trabalho de interpretação e analise, é fundamental um conhecimento profundo dos fatos a serem analisados. Por este motivo, no item 3 será feita uma dissertação sobre a orientação contábil existente anterior ao referido pronunciamento do Financial Accounting Standards Board, FASB. Este tópico visa a dar embasamento a discussão do tem 4, que trata dos problemas deste arcabouço inicialmente considerado.

No item 5 será realizada uma apresentação minuciosa dos aspectos teóricos emanados no pronunciamento. Será dada maior atenção aos pontos em que o Board realmente trouxe inovações a estrutura existente: dessa forma, os aspectos que já foram abordados por outros pronunciamentos do FASB ou de outros órgãos cio normatizacão e regulamentação não serão considerados.

E importante esclarecer que este artigo possui expectativas somente teóricas não procurando abordar problemas práticos e de rotinas de contabilização e controle. Tal enfoque deriva da extensa gama de considerações praticas e teóricas realizadas pelo novo pronunciamento, o que impossibilita uma abordagem tão abrangente num artigo devido as delimitações de espaço características.

$\mathrm{Na}$ seleção daquilo que consistiria a amostra dos procedimentos e orientações contábeis anteriores ao SFAS 133, para comparação, foram utilizadas informações emanarias dos seguintes organismos classificados por abrangência geográfica:

- América do Norte: FASB. Securitíes and Exchange Commission (SEC) e American Institute of Certífied Public Accountants

[AICPA).

- Brasil: Banco Central do Brasil (BACEN) e Comissão de Valores Mobiliários (CVM):

- Aspecto Internacional: International Accounting Standards Committee (IASC). Bank of Internatíonal. Settlements (BIS). 
Internationa/ Organization of Securities Exchange Comssions (IOSCO).

A escolha destas instituições se deveu unicamente a percepção do autor de que estes organismos forneceram as mais importantes contribuições ao estudo da contabilização de derivativos pré SFAS 133, sendo que a escolha nas instituições brasileiras decorre de motivos lógicos de interesse do publico nacional.

Não será realizada nenhuma explanação a respeito na operacionalização destes instrumentos, pressupondo um conhecimento básico do leitor a respeito cio assunto, devido a questão do escopo do trabalho realizado.

Alguns termos técnicos serão utilizados na sua versão original em inglês sem que seja feita uma tradução. Esta postura se deve a dificuldade inerente de tradução de algumas terminologias técnicas e a sua ampla utilização no mercado brasileiro.

\section{$\underline{\text { Justificativas }}$}

Um trabalho no desta natureza possuí duas classes de justificativas básicas. a saber:

1.Justificativas de Natureza Operacional: apesar deste :trabalho ser de natureza eminentemente conceitual, algumas demandas advindas da atividade profissional de contabilidade configuraram a necessidade de uma resposta teórica esta constatação e resultado de algumas praticas amplamente utilizadas no mercado que ainda não possuem, ou possuíam, urna resposta conceitual adequada. Assim temos:

- ambiente institucional - os instrumentos derivativos em suas varias categorias vêm sendo negociados com intensidade cada vez maior nos mercados mundiais, de forma que as operações consolidadas ia abancam alguns trilhões ou dólares de valor nocional somente nos Estados Unidos. O Brasil possui um mercado bastante ativo de negociação destes produtos através da Bolsa de Mercadorias e Futuros (BM\&F) que se coloca constantemente entre as dez maiores bolsas ou derivativos do mundo. Juntamente a este volume vigoroso de operações, ocorreu uma serie de problemas financeiros com instituições que se utilizaram destes produtos; casos como os do Barings, Metallgesechaift, Procter \& Camble, Daywa, Securites, Orange County e outros se tornaram celebres na literatura financeira devido aos volumes envolvidos nos prejuízos e na ausência de uma explicação clara a respeito das reais causas aos problemas. Esta situação vem preocupando autoridades financeiras internacionais que reconhecem a própria falta de competência para regulamentar e controlar a operação destes produtos, como pode ser observado pelos pronunciamentos do General Acccunting Office (GAO) ${ }^{1}$ e do $B I S^{2}$;

- mecanismos de controle gerencial - existe um consenso no

\footnotetext{
${ }^{1}$ General Accounting Office - GAO, Special report to US Congress on financial instruments and capital markets.

${ }^{2}$ Bank of International Settlements - BIS.. A survey on derivative disclosures by international banks.
} 
mercado financeiro de que os atuais mecanismos de controle gerencial das instituições não estão perfeitamente adaptados as operações com derivativos realizadas. A maioria dos sistemas ao controle não esta adaptada às características de alta volatilidade e elevado volume nocional ${ }^{3}$ destes produtos. Desta forma surge uma demanda natural por propostas advindas da academia no sentido de resolver tais questionamentos. A criação de um modelo gerencial realmente eficiente passa pelas etapas de reconhecimento das operações, mensuração, acumulação, evidenciação e definição de limites operacionais e de autonomia de forma a possibilitar aos gerentes das empresas, uma visão realmente integrada de todo o processo de operação de instrumentos financeiros e da própria gestão de riscos integral:

- evidenciação - a ausência de um corpo teórico contábil definido em relação aos instrumentos derivativos prejudicou sobremaneira a evidenciação destes produtos. Para profissionais como analistas de mercado de capitais, autoridades de regulamentação e fiscalização, gerentes de crédito e demais usuários externos da informação contábil, a obtenção de informações sobre o nível de utilização de instrumentos derivativos das empresas analisadas se tornou uma questão insolúvel, com raras exceções. Assim, a reposta conceitual para o tratamento contábil destes instrumentos se mostra extremamente relevante.

- JustificativaS de Natureza Estritamente Conceitual: a seguir são apresentadas algumas questões conceituais que não haviam sido respondidas pelo arcabouço teórico anterior ao SFAS 133. Dessa forma, estes pontos principais reforçam a importância do referido pronunciamento uma vez que a resposta conceitual coerente se constitui num dos passes mais importantes para que uma prática contábil possa ser amplamente divulgada e aceita pela comunidade envolvida. Assim:

- definição de instrumento derivativo - havia varias definições de instrumento derivativo sem que uma delas oferecesse a qualidade técnica exigida para possuir uso disseminado pelo mercado e pela academia. Esta ausência é muito importante, já que a classificação de um determinado instrumento como derivativo ou não é o ponto de partida para o processo de informação contábil. Este problema dificulta a comunicação contábil de forma considerável, uma vez que o próprio objeto da analise não estava bem definido:

- definição de ativos e passivos - não havia um consenso a respeito do reconhecimento das diversas operações possíveis com derivativos dentro das classificações habituais de Ativos e Passivos. Este ponto decorre principalmente da dificuldades de identificações dos direitos e das obrigações das instituições naquilo que concerne aos valores nocionais das operações. Existe a impressão inicial, decorrente do fato de o valor nocional ser somente uma referencia rara obtenção dos valores realmente liquidados, de que não na a caracterização de direitos ou obrigações. Esta situação inicial era bastante pobre conceitualmente, uma vez que o desconhecimento dos valores a serem liquidados não implica, necessariamente, na descaracterização ao ativo os passivo. Para o reconhecimento destas operações considerou-se que toda a operação de qualquer

${ }^{3}$ Ou National Value . Valor dos contratos vezes o montante; serve de base para a liquidação do mesmo. 
derivativo que enseja uma obrigação ou direito, urna vez que se não fosse assim não haveria motivo para a referida transação: todos os agentes neste tipo de mercado, sejam eles especuladores, arbitradores ou hedgers ${ }^{44}$, procuram algum tipo de direito e para isso assumem algumas obrigações, como é natural de uma operação comercial:

- mensuração do fair value - anteriormente a este pronunciamento havia uma enorme duvida a respeito de qual seria o melhor valor a ser atribuído as operações ao derivativos no processo de mensuração contábil. Nau estava Claro, até aquele momento, qual metodologia deveria ser adotada e nem mesmo qual seria o melhor critério: custo histórico, valor de mercado, fair value. etc. Este problema consistia em um aos inviabilizadores de um processo de reconhecimento contábil mais eficiente:

- ausência de um arcabouço único - pronunciamentos intermediários do FASB. Emerging Issues Task Force (EITF), pronunciamentos do AICPA, normas da SEC. instruções e circulares da Comissão de Valores Mobiliários - CVM e Banco Central do Brasil, recomendações do BIS e ao IASC: todos estes órgãos forneceram, de alguma forma, tentativas de orientar os praticantes a respeito do tratamento contábil dos derivativos. Apesar das obrigações legais, muitos pronunciamentos com excesso de informações. quase sempre conflitantes, levou o mercado a uma grande confusão para determinar qual o tratamento que realmente possuía melhor embasamento conceitual. O elevado numero de orientações se deve a uma ausência de consenso, muitas vezes, não só externa, como também dentro dos próprios organismos de orientacão e normatizacão:

- definições conflitantes e de difícil aplicação pratica decorrentes, basicamente, do exposto acima as varias definições falharam em apresentar um mecanismo de contabilização que aliasse uma certa coerência conceitual a uma aplicabilidade viável ao dia-a-dia das operações:

- mensuração e reconhecimento do resultado - uma vez que não ha uma definição correta aos instrumentos, conceitualmente não ha um arcabouço de contabilização definido e a mensuração dos mesmos ainda não foi bem estruturada: a questão ao reconhecimento das receitas e despesas se torna praticamente inviável.Torna-se critico saber o momento e a forma de contabilização dos derivativos para que o resultado da entidade esteja corretamente apresentado. Como o resultado de uma categoria de produtos contribui para a formação de resultado global na organização que, por sua vez, e um componente primário da determinação ao retorno ao investimento envolvido, a ausência de um arcabouço de mensuração adequado impossibilita uma correta determinação da relação de risco e retorno tão importante na alocação de recursos na economia. Pode-se observar então, que os problemas de evidenciação de derivativos associados as dificuldades com mensuração de resultado prejudicam sensivelmente a determinacão de um trade- off de risco e retorno adequado para as instituições.

Tratamento Contábil da Operacões com Derivativos Anteriores aos SFAS 133.

4 Agentes que procuram proteção (hedge) contra flutuações de preços e taxas na economia. 
Neste tópico será apresentado, de uma forma geral, o tratamento contábil das operações com derivativos dentro das orientações anteriores ao SFAS 133. Esta apresentação está dividida em tens, os quais serão analisados na parte referente as inovações advindas do referido pronunciamento para que o leitor possa se realizar uma comparação, assim:

- ambiente institucional - como já discutido, há uma grande indefinição entre as autoridades reguladoras, organismos de classe, comitês de orientação, etc. , a respeito do tratamento contábil dos derivativos. No entanto. pode-se ilustrar os exemplos meritórios do FASB e do IASC que constituíram comissões especialmente desenhadas com a finalidade de formar um arcabouço que viesse a sanar as questões decorrentes da operação destes instrumentos, Especificamente no caso do FASB, o SFAS 133 é resultado de anos de intensa pesquisa e debate que consumiram muitos esforços e recursos em geral:

- definição dos instrumentos - as definições anteriores eram basicamente advindas da Teoria de Finanças e não faziam menção significava aos derivativos sobre o ponto de vista contábil. A maioria delas era bastante incompleta, permitindo muitas confusões e diversas interpretações, como por exemplo: derivativo é todo instrumento cujo valor deriva do valor de um outro instrumento financeiro: definição bastante utilizada, mas pouco rigorosa. Esta lacuna dificultava bastante 0 restante do processo de reconhecimento contábil uma vez que os produtos nem sequer eram caracterizados. Cabe ressaltar que nenhum aos grupos acima considerados ofereceu uma definição que realmente tivesse o rigor metodológico necessário:

- reconhecimento - as operações com opções constituem-se em ativos para os seus titulares? $\mathrm{E}$ os lançadores das mesmas? Questões como estas permeavam constantemente o processo de mensuração e informação contábil de todos os profissionais envolvidos neste mercado de derivativos. Nesta discussão. vários pronunciamentos internacionais eram contrastantes como ocorre em relação ao Banco Central do Brasil que não prevê a contabilização das opções como ativos enquanto que os primeiros exposures drafrs $^{5}$ do FASE indicavam aquela direção. De uma forma geral a maioria das normas regulamentadoras não considerava os derivativos como posições dentro ao balanço patrimonial caracterizando as operações como off-balance sheet Este ponto constitui-se num dos principais problemas do arcabouço contábil anterior ao SFAS 133, uma vez que as operações acabam escapando de qualquer forma de mensuração e controle contábil, simplesmente não sendo consideradas para fins de elaboração do balanço patrimonial.Teoricamente, o desafio surge no momento da definição de ativos e passivos: as características aos derivativos se adequam as definições consideradas? Existe um problema com os conceitos atualmente existentes? Será necessária uma redefinição conceitual de elementos fundamentais do corpo teórico na Contabilidade. Questões como a exemplificada permaneceram sem respostas por muito tempo;

- mensuração - qual é o valor real de um derivativo? Será o seu valor de negociação apropriado? Como atingir o valor justo? Com os problemas de definição, anteriores, é bastante complicado atingir um modelo de mensuração, adequado a estrutura dos Princípios Contábeis Geralmente Aceitos. Tal assertiva decorre das

${ }^{5}$ Relatórios intermediários para discussão visando futuros Statements 
características intrínsecas dos derivativos: alta volatilidade e valor nocional distante muitas vezes do valor de liquidação efetiva. Assim, não existem modelos que ofereçam medidas objetivas do real valor de um derivativo: o problema se agrava, pois o custo histórico não fornece uma informação relevante para estes instrumentos devido as características já mencionadas. Este era outro ponto bastante importante que permaneceu sem uma orientação definitiva de consenso:

- reconhecimento de receitas e despesas -como uma decorrência natural do exposto, é difícil desenvolver um modelo de apuração de ganhos e perdas, bem como reconhecimento das receitas e despesas de um instrumento financeiro que não esta perfeitamente definido e cujo valor real e quase uma incógnita. Assim, as questões relativas ao reconhecimento do resultado acabaram sendo pouco endereçadas. Várias abordagens foram tentadas: apuração de acordo com a liquidação financeira, variação do valor de mercado, modelos de mensuração de fluxos futuros de caixa, etc. No entanto, este problema permaneceu sem uma orientação definitiva:

- disclosure - o SEC realizou uma importante contribuição para a evidenciação aos instrumentos derivativos quando passou a exigir que todas as companhias apresentassem um modelo de dtsclosure de risco quantitativo. Nos outros grupos analisados, as exigências de evidenciação estavam sempre relacionadas aos aspectos gerenciais da política na gestão de riscos na empresa. No entanto, a SEC se pronunciou exigindo a evidenciação quantitativa do risco das operações nas seguintes formas: tabular, analise de sensibilidade e value-at-risk. A primeira delas somente exige a evidenciação nas operações realizadas e os respectivos prazos e taxas das mesmas: a apresentação com análise de sensibilidade requer as mesmas informações anteriores, acrescentando-se a resposta ao valor aos derivativos as variações nos preços e taxas as quais os mesmos estão relacionarias. A metodologia do Va!ue-atRisk (VAR) considera uma metodologia estatística mais sofisticada na qual se estima, sob condições de distribuição normal ou lognormal, a perna máxima possível num dado intervalo de tempo com um certo grau de significância. De uma forma geral, o nível de evidenciação quantitativo exigido pela SEG supera o equivalente requisitado por outras correspondentes da agência americana. Pode-se inclusive, considerara trabalho da SÉC, em muitos aspectos, superior ao apresentado pelo SFAS 133. como será visto adiante.

\section{Problemas do Arcabouco Contábil Existente Anterior ao SFAS 133}

Como foi exposto, o tratamento conferido as operações com derivativos do ponto de vista contábil apresentava inumeros pontos deficientes. Estas deficiências trouxeram uma série de problemas tanto conceituais e teóricos como operacionais, para toda a comunidade envolvida com estes instrumentos financeiros. Acerca do corpo banco, tem-se os seguintes tópicos deficientes:

- perda de relevância da informação contábil - este primeiro problema ocorre tanto dentro ao escopo da informação gerencial 
(usuário interno), quanto da informação para os usuários externos. Para os usuários externos, o não aparecimento nos produtos nos balanços cria a simples ausência da informação prejudicando, sobremaneira, qualquer utilização nos balanços para fins de análise, isto é, alguns instrumentos simplesmente não são mostrados. A ausência de evidenciação quantitativa de risco, na maioria dos países, leva também a impossibilidade de qualquer previsão e inferência a respeito do risco nas operações e das instituições como um todo. Aliados a estes problemas, existe a dificuldade de mensuração nestes produtos, juntamente com os critérios ainda não definidos ao reconhecimento da receita e da despesa. Com base neste cenário, verifica-se que do ponto de vista dos derivativos, a informação contábil oferecia pouca ou nenhuma informação para os usuários externos perdendo naturalmente a relevância. Neste grupo de usuários prejudicados, tem-se analistas de mercado de capitais, instituições financeiras, autoridades governamentais, organizações não governamentais e o público em geral. Para os usuários internos (informações gerenciais). o problema e bastante semelhante uma vez que gerencialmente também não foram desenvolvidos aos modelos que suprissem todas as necessidades de informações dos administradores; o grande numero de modelos utilizados são basicamente de natureza estritamente financeira sem possuir uma ligação formal com relatarias de informação contábil. Mais uma vez observa-se a perda de relevância da informação contábil sendo substituída por modelos exclusivamente financeiros e totalmente desligada dos relatórios advindos da controladoria. Pode-se observar que o conceito de middle-office (controladoria pro-ativa), apesar de bem divulgado nos meios acadêmicos, e pouco empregado no dia a dia operacional das empresas. Sob a visão estritamente acadêmica não foram elaborados modelos que oferecessem uma alternativa viável para o controle gerencial destes produtos, sendo dessa forma a única alternativa para os praticantes o desenvolvimento de modelos eminentemente práticos. É natural que, com este quadro, os modelos internos de controle não sejam conceitualmente os mais rigorosos e dessa forma sujeitos a muitas falhas, como o caso do banco inglês Barings pode atestar. Pode-se concluir que a contabilidade falhou no seu objetivo de fornecer informações relevantes, com os seus dois grupos de usuários:

- critica à estrutura conceitual da Contabilidade - o questionamento nasceu da preocupação a respeito das razões da inabilidade da contabilidade para tratar as operações com derivativos. Este problema advém de uma lentidão dos profissionais envolvidos em adaptar 0 atual arcabouço teórico às características destes novos produtos ou será o corpo teórico simplesmente insuficiente para o tratamento contábil de tais derivativos? Vários problemas surgiram, cuja principal causa e urna inadequação dos princípios contábeis geralmente aceitos para mensurar o real valor de algumas transações com derivativos. O custo histórico, por exemplo, já vinha sendo criticado em relação a outras operações: no entanto, foi com os instrumentos financeiros em coral e os derivativos, em particular. que o custo histórico perdeu definitivamente a relevância. As características intrínsecas dos derivativos, como elevada volatilidade, tornam o valor de aquisição de um produto pouco relacionado com o seu valor real. Outro problema surge da própria 
estrutura das partidas dobradas; será realmente que as informações duplas fornecidas segundo esta metodologia refletem todas as características econômicas destes produtos? E o risco da operação? Surge, naturalmente, a questão a respeito da adequação da estrutura nas partidas dobrarias a estes novos produtos. Seria a resolução destes problemas possível dentro da estrutura atual de mensuração e evidenciação contábil? $O$ atual trabalho ao FASB propõe uma resposta a estes problemas na atual estrutura contábil com evoluções significativas, ou será uma proposta de uma nova estrutura? As respostas a estas quesțões serão indicadas no tópico referente ao conteúdo do SFAS 133. E importante ressaltar que esta duvida, explicitada, ainda permeiam varias discussões, principalmente nos ambientes acadêmicos.

\section{Propostas do SFAS 133}

O Statement of Financial Accountíng Standards 133 (SFAS 133): Accounting for Derivative Instruments and Hedqing Activities propõe uma estrutura conceitual para a contabilização e dísclosure das operações com derivativos. Existe uma série de considerações operacionais a respeito de aplicações do mesmo bem como quais as relações deste Statement com outros pronunciamentos do FASB. Neste trabalho tais considerações

não serão analisadas, mas, somente a titulo de apresentação, dois pontos operacionais importantes deste pronunciamento são relevantes para a analise, a saber:

- aplicável a todas as entidades - isto é, o arcabouço apresentado tem a abrangência de todas as empresas, excetuando-se somente algumas organizações sem fins lucrativos. As conseqüências desta colocação são que, as mais variadas empresas, mesmo as que não possuem operações financeiras intensamente, terão que se adequar ao novo Statement. Esta colocação e muito importante e bem - vinda em relação a idéia anterior de uma orientação somente para as instituições financeiras, considerando que as outras empresas não possuíam necessidades significativas de contabilização e evidenciação; algumas empresas pedem apresentar maior risco com uma única operação de opção de venda, por exemplo, numa posição lançadora, do que com toda a sua atividade comercial. A pratica elucida nem esse problema com os casos de empresas como a Procter \& Gamble e a Metallgesechafft que apresentaram grandes prejuízos em operações com derivativos, mesmo não sendo instituições financeiras. O caso do Orange County é o extremo desta consideração:

- relação com outros pronunciamentos -este Statement revoga os SFAS 80, 105 e 119. Realiza alterações nos SFAS 52. 60. 65, 97, $107,115.125$ de forma importante, bem como uma serie de outras alterações menores em vários outros pronunciamentos. $\mathrm{E}$ valido a partir de 15 de junho de 1999 (ano fiscal americano), mas a sua aplicação anterior a esta data e encorajada. Assim, pode-se observar a influência destes Statement por intermédio do grande numero de pronunciamentos que ele altera. No que concerne à mensuração do fair value o SFAS 133 se baseia integralmente no arcabouço do SFAS 107 - Disclosure about Faír Value of Financial Instruments de forma que este é o pronunciamento mais lembrado na estrutura do novo pronunciamento do FASB. 
Do ponto de vista conceitual pode-se elencar os seguintes pontos importantes do SFAS 133, e sua respectiva explicação, a saber:

- definição clara dos instrumentos derivativos - segundo o FASB, instrumento derivativo e todo aquele contrato que possui um ou mais underlyings e um ou mais valores nocionais (determinando a liquidação financeira do contrato) e não existe um investimento inicial no contrato, ou ele e muito menor do que o respectivo para que os participantes obtenham os mesmos direitos e a mesma sensibilidade a variações de mercado: bem como é esperado que ocorra liquidaçẳo financeira do mesmo no contrato, ou ele fornece meios para que a entrega de um ativo cumpra o mesmo papel. Dessa forma percebe-se que o FASB apresenta uma definição clara e objetiva para estes instrumentos e exclui uma serie de operações do escopo do tratamento dos derivativos. Esta definição é extremamente relevante, pois permite uma assertiva direta a respeito do tratamento a ser aplicado aos produtos considerados:

- reconhecimento dos derivativos como Ativos e Passivos - todas operações com derivativos fornecem direitos e obrigações para os seus participantes e dessa forma devem ser reconhecidos no balanço patrimonial. Para isto o FASB se apóia na definição de Ativos e Passivos emanada no FASB: Concepts Statements 6. E/ements of Financial Statements, em que os Ativos devem conferir benefícios futuros a entidade que os detém, exclusividade na operação e a respectiva transação já tenha ocorrido. Para os Passivos têm-se a responsabilidade presente ou futura, particularidade e o evento gerador a tenha sido realizado. Dessa forma, o FASB elimina os problemas das operações off-balance sheet com o reconhecimento de qualquer operaçã̃o nos balanços patrimoniais. A abordagem adotada pelo FASB é bastante lógica, uma vez que contratos de liquidação futura sempre ensejam direitos e obrigaçōes aos seus participantes: o problema sempre foi como mensurar e reportar tais instrumentos: este ponto será abordado a seguir:

- mensuração dos derivativos pelo fair value - o FASB orienta que - fair value é a melhor medida de mensuração de instrumentos financeiros e a única medida possível para os derivativos. Dessa forma, todos os derivativos devem ser reconhecidos nos balanços de acordo com o fair value dos direitos e das obrigações conferidos aos participantes. A melhor medida de valor justo é considerada o valor de mercado dos produtos que forem negociados em bolsas de derivativos e similares. Para os derivativos que não possuírem esta característica de negociação podem ser usados vários modelos para a obtenção destes valores: valor presente de fluxos futuros de caixa. precificação de opções (Black \& Scholes por exemplo), modelo binomial e vários outros: analogias com outros instrumentos também podem ser feitas. No entanto, é fundamental que os modelos adotados estejam bem explicitados nas notas explicativas e que a sua aplicação seja consistente ao longo dos períodos. Pode-se considerar que este e um passo importante da Contabilidade, uma vez que esta se abrindo a hipótese da contabilização de um valor estimado que não e necessariamente objetivo: inclusive, se os modelos de precificação fornecessem medidas seguras de preço destes produtos não haveria mercado para tal negociação:

- classificação dos produtos de acordo com a finalidade para a 
qual eles foram adquiridos - o Board decidiu por adotar as seguintes classificações para as operações de derivativos de acordo com a finalidade para a qual a entidade os adquiriu ${ }^{6}$.

1. hedge de uma exposição a mudanças no fair value de um ativo ou passivo a reconhecido ou de um compromisso firme ainda não reconhecido (falr value hedge);

2. hedge de uma exposição a fluxos de caixas variáveis de uma transação futura projetada (cash flow hedging):

3. hedge de uma exposição a uma moeda estrangeira de um investimento em uma operação internacional, um compromisso ainda não reconhecido, um titulo destinado a operação de trading instituição ou uma transação esperada denominada em moeda estrangeira:

4. instrumentos não designados como instrumentos de hedge. Estes instrumentos são aqueles que a instituição adquire com 0 propósito de obter resultados positivos com as flutuações de preços e taxas.

Esta classificação possui uma importância enorme, pois orienta todo o tratamento contábil subseqüente destes produtos.

- a contabilização dos ganhos e perdas com estes produtos (variações de fair value) depende da intenção no uso do instrumento e de sua respectiva classificação - Para cada uma das classificações apresentadas o SFAS 133 determina uma forma especifica de reconhecimento dos ganhos e perdas para cada derivativo considerado. Dessa forma temos a seguinte orientação:

1. fair value hedge: os ganhos ou pernas são reconhecidos no resultado no período de variação. juntamente com o resultado do tem sendo protegido atribuído ao risco sendo considerado. Nesta metodologia, somente será levado ao resultado a parte não eficaz no processo de anulação das perdas ou ganhos no item protegido:

2. cash flow hedge: as variações são mostradas inicialmente como parte de outros ganhos. fora do resultado. e subseqüentemente reclassificado para o resultado. quando a transação futura vier a ocorrer:

3. hedge uma exposição em moeda estrangeira de um investimento em uma operação internacional: os ganhos ou perdas são classificados em outros ganhos. fora do resultado. como uma parte do ajuste acumulado da conversão. O modelo contabilização de fair value hedge. descrito. aplica-se para um derivativo designado

como hedge de urna exposição em moeda estrangeira ao um compromisso firme não reconhecido ou de um titulo utilizado para a operação normal da empresa. Da mesma forma. a Contabilidade ao um cash flow hedge. descrito acima. aplica-se para todos os derivativos designados como hedge de uma transação projetada em moeda estrangeira.

\section{4. instrumentos não classificados como}

hedge: neste caso os ganhos ou perdas são reconhecidos no resultado imediatamente.

- disclosure - sem grandes evoluções conceituas. o FASB exige a evidenciação nas operações de acordo com os critérios já mencionados. Possui uma grande evolução pragmática no conteúdo informativo em relação ao SFAS 119. mas completamente baseada no arcabouço teórico já elencado. Pode-se inclusive considerar que a normatizacão a respeito da evidenciação quantitativa ao risco

\footnotetext{
${ }^{6}$ Texto extraído do artigo "Contabilidade de operações com derivativos: Uma comparação entre o SFAS e o COSIF" do mesmo autor
} 
advinda ia SEC possui uma sofisticação conceitual muito maior.

Este conjunto de medidas no FASB aumenta consideravelmente o conteúdo informativo das demonstrações contábeis e o faz trazendo para a contabilidade instrumentos de mensuração e classificação não objetivos e divergentes da estrutura tradicional do custo histórico como base de valor. Representa uma evolução considerável no modelo contábil ate então existente.

Do ponto de vista estritamente conceitual. este trabalho tem na sua definição de ativos e passivos. na mensuração do fair value e na classificação dos derivativos para fins de análise e reconhecimento ao resultado as suas principais contribuições.

$\mathrm{Na}$ definição de elementos patrimoniais. percebe-se uma clara evolução no sentido no fornecer abertura maior para a contabilização de instrumentos cujo reconhecimento não seja totalmente objetivo e direto. As opções. por exemplo, possuem comportamento de preço influenciando por varias incógnitas. entre as quais o preço do ativo direto e somente mais uma. sendo a volatilidade o seu determinante mais importante: neste tipo de operação não ha o menor sentido em reconhecer um instrumento dessa natureza pelo seu custo histórico. uma vez que a sua precificação não é uma relação direta deste preço. Assim. o FASB abre espaço para o reconhecimento de direitos que possuem uma natureza relativa em contrapartida a outros ativos (inderlying) ${ }^{7}$

Como já fora mencionado anteriormente, a importância do FASB para a contabilidade mundial, com vários paises adotando suas recomendações. em geral e para a contabilidade americana, em particular. É muito grande. Importância incrementada pela atenção que o mercado americano de capitais confere aos seus padrões contábeis. regularmente divulgados como forcas de propulsão de um mercado eficiente. organizado e fomentador da economia como um todo ${ }^{8}$. Com base neste ambiente. 0 referido Board adota o fair value como melhor medida do valor dos derivativos; esta é uma atitude importante. pois o FASB e reconhecido pela importância dada a confiabilidade das informações produzidas e mesmo assim adota uma medida indireta, com base em modelos financeiros e suas hipóteses. como estrutura básica do processo de reconhecimento e mensuração contábil de um instrumento financeiro.

Esta atitude ao FASE merece uma leitura das intenções do Board. Como e característico desde a sua fundação, logo apos a crise do mercado de capitais de 1929. o FASB procura a melhor informação. para o investidor e demais usuários atuantes no mercado. Assim. vê-se a consideração clara ao que uma informação mesmo não sendo perfeitamente objetiva e verificável, pode ser a mais relevante para 0 usuário da informação contábil. Observa-se uma reformulação da estrutura tradicional das características qualitativas $\mathrm{cm}$ informação contábil como elas são tradicionalmente conhecidas $^{9}$; isto é, mesmo que pouco verificável o modelo de Black \& Scholes. por exemplo, e uma estimativa melhor do preço de uma opção do que o facilmente identificável custo histórico.

\footnotetext{
${ }^{7}$ Valor subjacente: que pode ser uma taxa de juros, um titulo ou um preço de uma commodity. Não é o ativo em si mesmo.

8 LEVIT, Arthur. The importance of higth quality accouting standards .In Inter American Development Bank, Whashington D.C. 1997
}

${ }^{9}$ SFAS 2 - Qualitative characteristics of accounting information 
E de enorme relevância a colocação de que os derivativos

Terão, como visto anteriormente, um tratamento contábil para 0 reconhecimento das perdas e ganhos de acordo com a finalidade para 0 qual eles oram adquiridos: assim. produtos iguais poderão ter tratamentos distintos. A importância reside no fato de que, alem. é claro, da precisão técnica que perfeitamente não julga correto a mensuração de elementos no resultado que estejam fazendo parte de uma operação de hedge independentemente, para a maioria dos contadores significa ter que conhecer pormenorizadamente as características operacionais destes instrumentos para que a referida classificação possa ser feita. Tem-se a institucionalização da necessidade do profissional contábil de realmente conhecer as características dos produtos em que está trabalhando: com certeza esta e uma atitude louvável que reduz em muno a possibilidade de que erros ocorridos no passado. por puro desconhecimento, voltem a ocorrer.

\section{Uma Nova Contabilidade ou uma Sofisticacão de Modelos Antigos}

Dentro do desenvolvimento de um trabalho desta natureza surge a seguinte questão: as alterações trazidas pelo FASB são uma sofisticação do modelo contábil tradicional ou se constituem numa alteração tão significativa que inviabiliza a estrutura anterior? Pode-se observar facilmente que a convenção da objetividade não possui mais espaço neste novo pronunciamento e que a inclusão do fair value como mecanismo básico de mensuração fere fatalmente o principio do custo como base de valor. Desta forma, avista-se um pronunciamento que altera significativamente algumas premissas básicas do modelo contam; tradicional.

No entanto. apesar ce tocas estas modificações teria-se que observar uma continuação desta tendência para que a estrutura conceitua básica da contabilidade fosse realmente alterada. Este pronunciamento é am passo decisivo nesta direção. mas precisa ter as suas conseqüências plenamente desenvolvidas e estudadas para que "vôos mais altos" possam ser lançados; por enquanto, pode-se tratar somente de uma tentativa meritória, mas isolada, como muitas vezes é característica do FASB.

\section{Conclusões}

Conceitualmente dentro do arcabouço conceitual ao SFAS 133. observa-se que o fair value finalmente se torna uma medida operacional de valor. deixando de uma vez por todas o espectro meramente acadêmico para se tornar usual no dia a dia das empresas. Verifica-se que o reconhecimento de ativos e passivos deixa de possuir uma faceta objetiva intrínseca para abrir espaço para mensurações relativas e que dependem de uma modelagem financeira e quantitativa complexa. Podese identificar um grande passo no sentido de uma alteração dramática na estrutura tradicional da contabilidade e um sepultamento definitivo do principio do custo como base de valor e da convenção da objetividade.

Tem-se um aumento significativo no conteúdo informativo das demonstrações contábeis. uma vez que elas passam a conter um numero 
maior de informações e as mesmas estarão a valores mas próximos da visão do mercado. Um desenvolvimento na preparação dos profissionais de contabilidade se torna relevante, uma vez que a sofisticação técnica cresceu bastante e o treinamento em finanças e métodos quantitativos se torna um requisito indispensável para o correto tratamento destes instrumentos.

Entende-se que, conceitualmente, o pronunciamento referido apresenta dois problemas sérios (desconsiderando as características aplicação pratica), a saber:

- desconsidera a evidenciação e contabilização quantitativa do risco das operações -este ponto já foi bastante abordado na regulamentação na SEC, de forma que se esperava um pouco mais do FASB neste assunto. Perde-se muito de conteúdo informativo com «a ausência desta orientação:

- somente considera a determinação da eficiência de uma operação de hedge ao nível da operação e não dentro do escopo de toda a organização - e uma das premissas básicas da gestão de risco que uma operação pode ser redutora de risco ao uivei micro e aumentar o risco da entidade como um todo e viceversa. Esta desconsideração do SFAS 133 pode trazer problemas justamente quando uma posição da organização for considerada um hedge de uma transação. por exemplo. e estiver ao mesmo tempo desprotegendo toda a estrutura de capital da empresa; condição bastante provável para instituições que possuem muitas operaçõ̃es com opções.

Futuras pesquisas podem ser realizadas no sentido de testar as hipóteses presentes no SFAS 133. Será realmente que o valor de negociação em bolsa e uma boa estimativa no fair value como sugere o Statement baseado na hipótese dos mercados eficientes? Até que ponto todo estes custo adicional realmente significa um melhora no conteúdo informativo das demonstrações financeiras? Quais as estratégias de hedge que serão melhor utilizadas e quais os modelos no precificação mais adotados em suas premissas?

Devido a forte ligação deste assunto com a Teoria de Finanças e a disponibilidade de informacões advindas nas comas de mercadorias e futuros, as pesquisas positivas são bastante indicadas, e testes econométricos e 0 modelo de equações simultâneas se adequam perfeitamente as características das series de dados em questão.

Resumo

Este trabalho realiza uma analise critica do arcabouço teórico do Statement for financial Accouting Standards (SFAS 133): Accouting for Derivative instruments and Hedging Activities. Inicialmente é feita uma comparação com o corpo teórico existente para em seguida ser desenvolvida a analise das principais contribuições deste pronunciamento. As conclusões refletem uma série de evoluções no sentido de trazer para a contabilidade informações mais relevantes menos presas a convenção de objetividade. O custo como base de valor não é considerado como representativo para o reconhecimento destes produtos.

O SFAS 133 representa uma grande evolução em termos conceituais e práticos. No entanto. comete algumas falhas ao não mencionar 0 disclosure quantitativo e não realizar urna analise $\mathrm{cm}$ eficácia do hedge dentro da perspectiva da entidade como um todo. Este pronunciamento 
abre uma serie de perspectivas para pesquisas futuras. principalmente sob o aspecto positivo e a utilização de técnicas quantitativas.

\section{Referências Bibliográficas}

BACEN - BANCO CENTRAL DO BRASIL . Circulares diversas

CARVALHO. Luiz Nelson Guedes. Uma contribuição para a auditoria de risco de derivativos. São Paulo, 1996. Tese (Doutorado) .Faculdade de Economia, Administração e Contabilidade - FEA/USP.

CVM COMISSÃO DE VALORES MOBILIARIOS. instruções diversas CMN CONSELHO MONETARIO NACIONAI Resolução Diversas.

FASB - Financial ACCOUNTING STANDARDS BOARD. Exposure draft: Accounting for derivatives and similar financial instruments and for hedging activies, 1996

LOPES, Alexsandro Broedel; Lima, Iran Siqueira. Análise comparativa dos procedimentos contábeis aplicados a operações financeiras com derivativos: Um estudo - Brasil vs. Estados Unidos. Resenha da Bolsa de Mercadorias e Futuros. São Paulo, № 121, janeiro 1998.

NAKAMURA, Ângela Mie. Contribuição ao Estudo dos procedimentos e evidenciação contábeis aplicáveis a operações com derivativos, voltados a Instituições financeiras. São Paulo, 1996. Tese (Doutorado), Faculdade de Economia, Administração e Contabilidade - FEA/USP.

PERRY, Raymond E. Accounting for derivatives. Chicago: Irwin, 1997.

RISK MAGAZINE. Várias edições.

SEC - SECURITIES AND EXCHANGE COMISSION. 1995. Proposed amendments disclosures of accounting policies for derivative financial struments and derivative commodity instruments and disclosure of qualitative and quantitative information about market risk in derivative financial instruments, other financial instruments, and derivative commodity instruments. Release $n^{\circ}$ 7250. December 28, 1995 Washington, D.C. securities and Exchange Comission; 61 FR 578, January 8, 1996.

1997. Diclosure of accounting policies for derivatives financial instruments and derivative of quantitative commodity instruments and disclosure of qualitative and qualitative information about market risk inherent in derivative financial instruments, and derivative commodity instruments. Releases no33-7386; 34-38223; IC- 224887; FR-48; International Series $n^{\circ}$ 1047, File noS7-35-95 (january 31, 1997) Whashington, DC: Securities and Exchange Commission. 
series. Release $n^{\circ}$ 268: Presentation in financial statements of redeemable preferred stock

SFAS - STATEMENT OF FINANCIAL ACCOUNTING STANDARDS.

SFAS 52: Foreing currency translation, 1991.

SFAS 80: Accounting for futures contracts, 1984

SFAS 107: Disclosure about fair value of financial instruments with concentrations of credit risk, 1990.

SFAS 115 - Disclosure about fair value of financial instruments, 1991

SFAS -119: Disclosure about derivative financial instruments and fair value of financial instruments, 1994

SFAS 123: Accounting for stock- based compensation, 1995

-SFAS133: Accounting for derivative instruments and hedging activies. 